\title{
PULSOS ELÉTRICOS NA PRESERVAÇÃO DE ALIMENTOS: FATORES CRÍTICOS NA INATIVAÇÃO MICROBIANA E EFEITOS SOBRE OS CONSTITUINTES ALIMENTARES
}

\author{
GEÍZAALVES DE AZERÊDO* \\ FERNANDO LUIZ NUNES DE OLIVEIRA** \\ ZELYTAPINHEIRO DE FARO***
}

\begin{abstract}
O presente trabalho teve como objetivo efetuar revisão da literatura sobre o tema pulsos elétricos na preservação de alimentos: fatores críticos na inativação microbiana e efeitos sobre os constituintes alimentares. Foram abordados os parâmetros do processo (intensidade do pulso elétrico, tempo e temperatura de tratamento), os atributos do produto (condutividade, força iônica, $\mathrm{pH}$ e atividade de água), as características dos microrganismos (tipo, concentração, estágio de crescimento) e os mecanismos de inativação, considerados como fatores críticos na eficiência de inativação microbiana do processo estudado. Foram também avaliados os efeitos do tratamento sobre a biodisponibilidade dos constituintes dos alimentos já que esse tipo de processamento opera mudanças estruturais na parede celular e pode afetar tanto a absorção quanto as propriedades bioativas dos mesmos. Os dados encontrados na literatura apontam o tratamento por pulso elétrico como alternativa promissora de preservação por se assemelhar ao processo de pasteurização e causar poucos efeitos sobre as características sensoriais e qualidade nutritiva dos alimentos, podendo ser utilizado como tecnologia única ou como complemento aos processamentos térmicos.
\end{abstract}

PALAVRAS-CHAVE: PRESERVAÇÃO DE ALIMENTOS; PULSOS ELÉTRICOS; INATIVAÇÃO MICROBIANA.

* Mestre em Ciência dos Alimentos, doutoranda em Ciência dos Alimentos, Universidade Federal de Pernambuco (UFPE), Professora, Escola Agrotécnica Federal de Vitória de Santo Antão, PE (e-mail: geazeredo@yahoo.com.br).

** Mestre em Agronomia, Universidade Federal da Paraíba (UFPB), doutorando em Ciência do Solo, UFPE, Professor, Escola Agrotécnica Federal de Vitória de Santo Antão, PE (e-mail: flno_oliveira@yahoo.com.br).

*** Mestre em Tecnologia de Alimentos, Universidade Federal do Ceará, Doutorado em Ciência dos Alimentos, UFPE, Professora, Departamento de Nutrição, UFPE, PE (e-mail: zelyta@oi.com.br). 


\section{INTRODUÇÃO}

Todos os alimentos e produtos alimentícios sofrem deterioração, dependendo de sua composição, formulação, embalagem e condições de estocagem. O potencial de deterioração está presente em qualquer estágio entre a aquisição da matéria-prima e o eventual consumo do produto acabado, podendo ser acelerado ou minimizado em qualquer um desses estágios. Os sistemas para completa preservação são geralmente multicomponentes, isto é, não dependem apenas dum fator para garantir a preservação (GOULD, 1995).

As principais reações de deterioração, que constituem o alvo da preservação, podem ser classificadas em: 1) físicas: relacionadas à umidade, levando ao enrijecimento da textura ou a hidratação; 2) químicas: oxidação (provocando rancidez oxidativa), perda da cor e reações de Maillard (causando descoloração e mudança na textura); 3) enzimáticas: gerando escurecimento enzimático (polifenoloxidades), rancidez oxidativa (lipoxigenases), rancidez lipolítica (lipases), gelatinização, mudanças no sabor e na textura (proteases); 4) microbianas: crescimento de microrganismos deteriorantes e patogênicos.

Embora a maior parte das técnicas de preservação tenha como meta controlar todas as formas de deterioração que possam acontecer, a prioridade sempre será minimizar a ocorrência e crescimento de microrganismos patogênicos (LINDGREN et al., 2002; GOULD, 1995).

O processamento térmico tem sido a técnica mais comumente usada para aumentar a vidade-prateleira e manter o alimento seguro pela inativação de microrganismos. Contudo, esse tratamento causa reações indesejáveis que alteram a qualidade dos alimentos (LADO e YOUSEF, 2002).

A preferência crescente dos consumidores por adquirir produtos com suas características preservadas tem impulsionado as pesquisas de novas tecnologias não-térmicas, como alternativa para eliminar ou minimizar a degradação qualitativa dos alimentos processados, particularmente dos tecidos vegetais. Esses apresentam perdas de pigmentos, sabor e vitaminas quando submetidos aos métodos térmicos (LINDGREN et al., 2002; DEVLIEGHERE, VERMEIREN e DEBEVERE, 2004; ARONSSON, RÖNNER e BORCH, 2005; LEBOVKA et al., 2005).

As vantagens dos tratamentos não-térmicos envolvem principalmente a baixa temperatura de processamento, menor gasto de energia, capacidade de retenção do sabor e nutrientes, promoção de frescor, além da inativação de microrganismos e enzimas (VEGA-MERCADO et al., 1997; ROSS et al., 2003). As tecnologias não-térmicas compreendem pulso elétrico, alta pressão hidrostática, luz pulsante, atmosferas modificadas e ainda compostos antimicrobianos (DEVLIEGHERE, VERMEIREN e DEBEVERE, 2004).

O tratamento por pulso elétrico representa alternativa promissora de preservação, uma vez que se assemelha ao processo de pasteurização sem o componente térmico. Embora tenha sido introduzido em 1960, recentes desenvolvimentos tecnológicos como o uso de câmara de tratamento contínuo tem estimulado e renovado o interesse por esse tratamento.

A proposta deste trabalho foi efetuar revisão de literatura acerca do tema pulsos elétricos na preservação de alimentos, com vistas a explicitar os fatores críticos que interferem no processo de inativação microbiana, bem como os efeitos desse tratamento sobre os constituintes alimentares.

\section{DEFINIÇÃO}

Pulso elétrico de alta intensidade refere-se à aplicação de pulsos de alta voltagem (geralmente $20-80 \mathrm{kV} / \mathrm{cm}$ ) em alimentos situados entre dois eletrodos (GÓNGORA-NIETO et al., 2002). O tratamento, conduzido em moderadas temperaturas durante menos de $1 \mathrm{~s}$, minimiza a energia perdida devido ao aquecimento dos alimentos (QIN et al., 1995).

Quanto aos atributos de qualidade, a tecnologia por pulso elétrico é considerada superior ao tratamento térmico convencional porque evita ou reduz as mudanças nas propriedades sensoriais e 
físicas dos alimentos. Embora isso já esteja comprovado, os efeitos químicos e nutricionais do pulso elétrico devem sempre ser levados em conta antes do seu uso em alimentos (QIN et al., 1995).

Alguns aspectos importantes na tecnologia por pulso elétrico são: a geração de altas intensidades elétricas, o desenho da câmara que deve conceder tratamento uniforme aos alimentos com aumento mínimo na temperatura, e a disposição dos eletrodos que minimizam o efeito da eletrólise. Altas intensidades são conseguidas mediante estoque de grande quantidade de energia em capacitor que a fornece e a descarrega na forma de pulsos (ZHANG et al., 1995).

\section{FATORES CRÍTICOS DA INATIVAÇÃO MICROBIANA}

A inativação microbiana por pulso elétrico depende de muitos fatores que são críticos para a eficácia do tratamento (Figura 1). Tais fatores podem ser classificados como parâmetros do processo (intensidade do pulso, tempo e temperatura de tratamento), atributos do produto ( $\mathrm{pH}$, compostos iônicos, condutividade) e características do microrganismo (tipo, concentração e estágio de crescimento).

\section{FIGURA 1 - FATORES CRÍTICOS QUE INTERFEREM NA INATIVAÇÃO MICROBIANA}

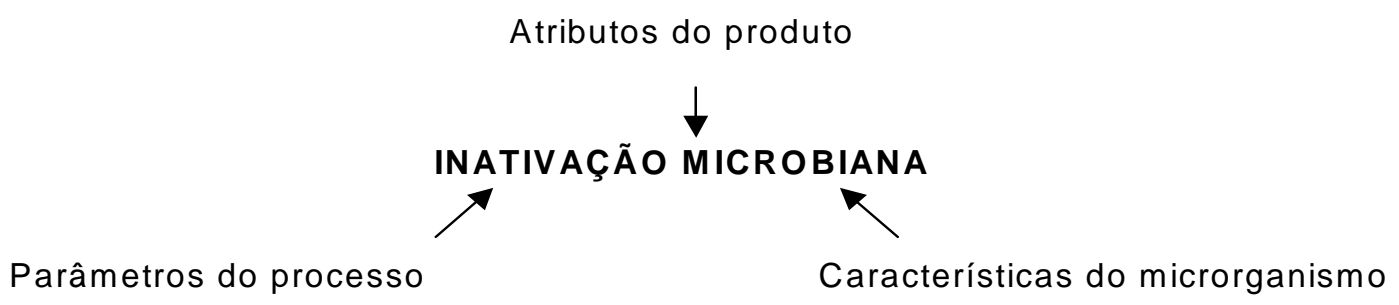

\subsection{PARÂMETROS DO PROCESSO}

\subsubsection{Intensidade do pulso elétrico}

A intensidade do pulso elétrico é diretamente proporcional à inativação microbiana, ou seja, quanto maior for a intensidade do pulso (acima do potencial de transmembrana crítico) maior será o grau de inativação (QIN et al., 1995). O potencial transmembrana natural da célula é de aproximadamente $1 \mathrm{~V}$. Se a intensidade do pulso for superior a esse limite ocorrerá, provavelmente, aumento da permeabilidade da membrana com formação de poros e eventual ruptura celular. Portanto, o Pulso Elétrico Crítico - Ec (intensidade de pulso elétrico abaixo da qual a inativação não ocorre) aumenta com o potencial transmembrana da célula (JEYAMKONDAN, JAYAS e HOLLEY, 1999).

\subsubsection{Tempo de tratamento}

Define-se o tempo de tratamento como o produto entre o número e a duração dos pulsos. $\mathrm{O}$ aumento em qualquer dessas variáveis eleva a inativação microbiana (SALE e HAMILTON, 1967). Maiores amplitudes requerem menores intensidades do pulso, que por sua vez resultam em maior inativação microbiana. Contudo, maior duração do pulso pode também resultar em aumento de temperatura indesejável no produto. Condições ótimas de processamento devem ser estabelecidas para se obter o mais alto nível de inativação microbiana com o mais baixo efeito do aquecimento (HÜLSHEGER, POTEL e NIEMANN, 1983).

\subsubsection{Temperatura de tratamento}

Resultados experimentais têm demonstrado que tanto a temperatura do tratamento quanto a temperatura do processo interferem na sobrevivência de microrganismos. Tratamentos com 
temperaturas moderadas (cerca de $50-60^{\circ} \mathrm{C}$ ) demonstraram efeito sinergístico sobre a inativação microbiana. Usando-se pulso elétrico constante, a inativação aumenta com a elevação da temperatura. Como a intensidade do pulso aumenta a temperatura dos alimentos é necessário resfriamento para manter a temperatura bem abaixo das geradas pelo processo de pasteurização (JAYARAM, CASTLE e MARGARITIS, 1992). Efeitos adicionais de altas temperaturas de tratamento incluem mudanças na fluidez e permeabilidade da membrana, que aumentam a susceptibilidade da célula à ruptura mecânica. Além disso, baixo potencial transmembrana decresce o Ec e aumenta a inativação (HÜLSHEGER, POTEL e NIEMANN, 1981).

\subsection{ATRIBUTOS DO PRODUTO}

\subsubsection{Condutividade, Força iônica, pH e Atividade de água (Aa)}

A condutividade elétrica do meio, definida como a capacidade de conduzir corrente elétrica, constitui importante variável no tratamento por pulso elétrico. Condutividade elétrica é o inverso de resistência. Alimentos com alta condutividade elétrica geram menores picos elétricos na câmara de tratamento, tornando inviável o uso desse tipo de tratamento. Estudos mostraram que aumento na condutividade do fluido reduz a resistência do tratamento, assim como a amplitude do pulso diminui a taxa de inativação. Aumento na condutividade eleva a força iônica do líquido, causando decréscimo na taxa de inativação. Além disso, quanto maior for a diferença entre a condutividade do meio e o citoplasma microbiano maior será o dano à estrutura da membrana, devido ao aumento no fluxo de substâncias iônicas através dela. Logo, a taxa de inativação de microrganismos aumenta com o decréscimo da condutividade. No entanto, ocorrem variações conforme o microrganismo ou o meio usado (JAYARAM, CASTLE e MARGARITIS, 1992).

$\mathrm{O} \mathrm{pH}$ atua como fator de estresse adicional, ao contrário da presença de cátions bivalentes que parecem exercer forte efeito sobre a redução da letalidade por pulso elétrico (MÁRQUEZ, MITTAL e GRIFFITHS, 1997). Quanto mais baixa for a atividade de água, maior será a resistência microbiana aos diferentes tratamentos ou agentes de inativação (ABABOUCH et al., 1995).

\subsection{CARACTERÍSTICAS DO MICRORGANISMO}

\subsubsection{Tipo de microrganismo}

As bactérias Gram-positivas são mais resistentes ao tratamento por pulso elétrico do que as Gram-negativas (SALE e HAMILTON, 1967). Isto pode ser atribuído à rigidez das camadas de peptideoglicano presentes na parede celular de bactérias Gram-positivas (LADO e YOUSEF, 2002). Fungos, geralmente, são mais sensíveis do que bactérias devido ao maior tamanho, embora pareçam ser mais resistentes do que as células Gram-negativas aos pulsos de menor intensidade (SALE e HAMILTON, 1967). Esporos, por serem menores e mais circulares, contam com certa proteção, sendo mais difícil inativá-los do que bactérias, leveduras e bolores (MÁRQUEZ, MITTAL e GRIFFITHS, 1997).

\subsubsection{Concentração de microrganismos}

O número de microrganismos no alimento pode alterar a inativação por pulso elétrico. O efeito da concentração microbiana sobre a inativação pode ter relação com a formação de colônias ou possivelmente por estarem localizados de maneira oculta, bem mascarados em regiões de baixa condutividade elétrica (HÜLSHEGER, POTEL e NIEMANN, 1983).

\subsubsection{Estágio de crescimento de microrganismos}

Em geral, células nas fases logarítmicas são mais sensíveis ao estresse do que aquelas na fase lag ou estacionária. O crescimento microbiano na fase logarítmica, caracterizado por alta proporção de células em estado de subdivisão é o período em que a membrana celular está mais susceptível ao pulso elétrico aplicado (HÜLSHEGER, POTEL e NIEMANN, 1983). 
Vários estudos têm sido publicados sobre a capacidade do tratamento por pulso elétrico inativar microrganismos. SALE e HAMILTON (1967) já haviam detectado a alta sensibilidade apresentada por Saccharomyces cerevisiae ao tratamento. Outras pesquisas comprovaram a eficácia do tratamento para reduzir cargas microbianas em até 9 ciclos logarítmicos, dependendo das condições e substratos usados (RODRIGO et al., 2001).

ARONSSON, RÖNNER e BORCH (2005) estudaram possíveis influências da permeabilização da membrana sobre o nível de inativação de células vegetativas. Comprovaram que maiores intensidades de pulso, associadas com maior tempo, aceleram o processo de inativação. O impacto do pulso mostrou-se espécie-dependente, sendo Saccharomyces cereviseae o organismo mais sensível, seguido por Escherichia coli e Listeria innocua. Observaram ainda que a severidade do tratamento na inativação das células vegetativas ocorre pela permeabilização de suas membranas, com formação de poros em sua superfície e subseqüente liberação de compostos intercelulares. Obtiveram, portanto, evidências de que a permeabilização da membrana celular está envolvida na inativação de células vegetativas de E. coli e $L$. innocua durante a exposição ao pulso. No caso de $S$. cerevisiae, a permeabilização da membrana não foi necessariamente letal e suas células não perderam a capacidade de multiplicação devido ao aumento da permeabilidade. $O$ aumento da inativação correspondeu para todas as espécies de microrganismos aos maiores números de células permeabilizadas, que se refletiu nas maiores quantidades de compostos intercelulares liberados. Os resultados sugerem que a permeabilização de células de $E$. coli e $L$. innocua, severamente danificadas pelo tratamento, foi letal.

A aplicação de pulsos elétricos em combinação com tratamentos térmicos moderados também tem sido testada. SEPULVEDA et al. (2005) evidenciaram redução significativa das populações bacterianas de Listeria innocua, sob circunstâncias em que nem o pulso elétrico em baixas temperaturas nem os tratamentos térmicos separadamente foram capazes de causar significante inativação bacteriana. Dessa forma, confirma-se a premissa de que a temperatura de tratamento constitui parâmetro muito importante quando se trata de inativação microbiana por pulso elétrico. Afirmaram que temperaturas de até $55^{\circ} \mathrm{C}$ são as mais indicadas para inativação de $L$. innocua em razão da fase de transição da temperatura dos fosfolipídeos na membrana celular. Sugeriram que a fase de transição de temperatura das membranas bacterianas poderia ser usada como parâmetro capaz de definir novos tratamentos por pulso elétrico em combinação com tratamentos térmicos moderados. Esse estudo oferece subsídios promissores para o uso de pulsos elétricos na preservação de alimentos.

\section{MECANISMOS DE INATIVAÇÃO}

Microrganismos são inativados quando expostos a fatores que alteram substancialmente sua estrutura celular ou funções fisiológicas (LADO e YOUSEF, 2002).

Várias são as teorias para explicar como ocorre a inativação microbiana. Uma delas justifica a inativação em termos de grande aumento na permeabilidade da membrana como resultado da formação de poros, induzida por potencial crítico entre 0.7 e $2.2 \mathrm{~V}$ (mais alto do que o potencial normal da célula $\sim 1 \mathrm{~V}$ ). A ruptura reversível ou irreversível da membrana depende de fatores já citados (intensidade dos pulsos, número de pulsos e duração dos pulsos). As membranas plasmáticas das células, após exposição ao campo elétrico, tornam-se permeáveis a pequenas moléculas levando a distorções no transporte de íons, dilatação e ruptura celular dependendo do grau de desordem na membrana (VEGA-MERCADO, 1997). Outra teoria, explica a inativação pelo acúmulo de cargas opostas criado pelo campo elétrico em lados opostos da parede celular microbiana, causando compressão e formação de membrana fina e instável. Há ainda a teoria da transição de poros hidrofóbicos para hidrofílicos, em que poros reversíveis tendem a tornar-se irreversíveis. Pela teoria da mudança conformacional, o campo elétrico induz transições de fases e conformacionais de lipídios e proteínas que poderiam conduzir à formação de poros transitórios (GÓNGORANIETO et al., 2002). Outros pesquisadores sugerem ainda a existência de diferentes mecanismos para a ação biocida da eletricidade. A descarga elétrica em meio líquido pode gerar pequenas quantidades de agentes microbicidas, como clorina, radicais livres e peróxido de hidrogênio $\left(\mathrm{H}_{2} \mathrm{O}_{2}\right)$ que alteram o DNA e 
a atividade citoplasmática durante o tratamento (HULSHEGER, POTEL e NIEMAN, 1981).

Deve-se salientar que a exposição repetitiva de contaminantes bacterianos aos processos de preservação gera desafio constante para a indústria de alimentos. Células adaptadas ao estresse e aquelas capazes de sobreviver aos processos com diversos fatores de preservação (teoria dos obstáculos) podem gerar mutantes ainda mais resistentes (HAUBEN et al., 1997).

\section{EFEITOS DA INATIVAÇÃO MICROBIANA POR PULSO ELÉTRICO SOBRE OS CONSTITUINTES DOS ALIMENTOS}

Embora a inativação de microrganismos por pulso elétrico de alta energia venha sendo extensivamente estudada (POTHAKAMURY et al., 1995; KEITH et al., 1997; SPERBER, 1998), pouco se sabe sobre os efeitos do pulso elétrico de alta energia (HELP) sobre proteínas e outros constituintes dos alimentos.

BARSOTTI et al. (2002) realizaram estudo com ovos e emulsões comerciais de óleo/água para determinar os efeitos do HELP sobre a proteína ovoalbumina, as emulsões de alimentos óleo/água e ainda sobre a atividade da enzima lactato desidrogenase (LDH). Não verificaram alterações na hidrofobicidade e, portanto, na capacidade geleificante da proteína. A estabilidade das emulsões não sofreu grandes alterações em razão da leve mudança no diâmetro dos glóbulos de gordura. Entretanto, sugeriram cautela ao tratar emulsões com cargas elétricas quando estabilizadas por proteínas que são particularmente dependentes da distribuição de suas cargas. A LDH não foi inativada por pulso elétrico, indicando que as interações eletrostáticas não foram dissociadas.

Proteínas também foram o alvo de estudo de PÉREZ e PILOSOF (2004). Investigaram a possibilidade de modificação protéica e o grau de sua extensão quando submetidas a longos pulsos de alta intensidade. Utilizaram como substratos as proteínas do ovo branco e a $\beta$-lactoglobulina. Sob as condições testadas, que envolveram extensos pulsos de alta energia, as proteínas do ovo branco mostraram-se mais resistentes ao tratamento do que a $\beta$-lactoglobulina. Esse comportamento está de acordo com os resultados obtidos em alta voltagem, porém com pulsos curtos e rápidos (FERNANDÉZDIAZ et al., 2000), indicando que a aplicação do pulso elétrico não afetou muito as propriedades de gelatinização das proteínas do ovo branco.

O modelo que explica os efeitos do pulso sobre as proteínas envolve a polarização da molécula protéica; a dissociação das ligações não-covalentes que unem as subunidades numa estrutura quaternária; as mudanças na conformação protéica expondo os grupos sulfidrila e os aminoácidos hidrofóbicos; e a tendência de atração de estruturas polarizadas por forças eletrostáticas. Se a duração do pulso for grande o suficiente, as interações hidrofóbicas e as ligações covalentes podem ocorrer formando agregados (PÉREZ e PILOSOF, 2004).

Espera-se que as vitaminas sejam preservadas, já que o pulso elétrico não constitui tratamento térmico (GRAHL e MÄRKL, 1996; BENDICHO et al., 2002). Em estudo com leite, realizado por QIN et al. (1995), suas propriedades físico-químicas e sensoriais não foram influenciadas por esse tratamento.

BENDICHO et al. (2002) avaliaram o efeito do pulso elétrico sobre as vitaminas hidro (riboflavina, tiamina e ácido ascórbico) e lipossolúveis (colecalciferol e tocoferol) do leite. Não relataram mudanças no conteúdo vitamínico, com exceção do ácido ascórbico que apresentou maior retenção $(93,4 \%)$ no tratamento por pulso elétrico do que a pasteurização a $63^{\circ} \mathrm{C} / 30^{\prime}(49,7 \%)$ e a $75^{\circ} \mathrm{C} / 15 \mathrm{~s}(86,7 \%)$.

BAZHAL, LEBOVKA e VOROBIEV (2001) tratando suco de laranja por pulso elétrico verificaram retenção de todas suas propriedades físicas e cerca de $97,5 \%$ de vitamina C. No entanto, restou a preocupação acerca do impacto que o processamento por pulso elétrico exerce sobre os efeitos benéficos do suco de laranja à saúde. Sabe-se que esse tratamento em vegetais resulta em efetiva permeabilização de membranas celulares e, em alguns casos, ruptura de sua integridade estrutural. Tal preocupação influenciou a realização de outro estudo para observar se as mudanças estruturais nas paredes celulares seriam capazes de afetar a absorção intestinal de compostos bioativos contidos em produtos tratados por 
pulso elétrico. SANCHÉZ-MORENO et al. (2004) buscaram analisar a biodisponibilidade da vitamina C e os níveis de isoprostana - 8epiPEF ${ }_{2 \alpha}$, após o consumo de suco de laranja fresco ou tratado por pulsos. A ingestão diária de $500 \mathrm{~mL}$ do suco tratado foi associada com significativo aumento da concentração de vitamina $\mathrm{C}$ e decréscimo nos níveis de 8epiPEF ${ }_{2 \alpha}$ no plasma. A vitamina $\mathrm{C}$ mostrou-se significativa e inversamente correlacionada com a isoprostana investigada. Esses efeitos foram similares aos obtidos com o suco fresco. Pode-se então supor que a tecnologia por pulso elétrico preserva as características do suco de laranja no que se refere à biodisponibilidade da vitamina $\mathrm{C}$, que permanece em sua forma ativa (Lascórbico), e às propriedades antioxidantes do suco fresco.

\section{CONSIDERAÇÕES FINAIS}

O tratamento por pulso elétrico representa alternativa promissora de preservação de alimentos, devido vantagens como a baixa destruição do sabor e de nutrientes. Também atinge o objetivo principal da indústria de alimentos, ou seja, oferecer aos consumidores produtos saudáveis com características de frescor. Pulso elétrico pode ser usado como tecnologia única, como ‘obstáculo' nos métodos combinados, ou ainda como complemento aos processamentos térmicos para preservação de alimentos.

\section{ABSTRACT \\ ELECTRIC PULSES IN FOOD PRESERVATION: CRITICAL FACTORS IN MICROBIAL INACTIVATION AND EFFECTS ON FOOD NUTRIENTS}

The present work had as objective to present a review about the use of the Pulsed Electric Fields Technology on food preservation: critical factors on microbes inactivation and effects on food constituents. The process parameters (pulsed electric fields intensity, time and temperature of the process), the product's attributes (conductivity, ionic state, $\mathrm{pH}$ and water activity), microbes characteristics (species, concentration, growth stage) and the inactivation mechanisms which are consider as critical factors for the microbial inactivation efficiency of the process were demonstrated. The effects of this process on food constituents' bioavailability was also evaluated since this process may affect the cellular membrane structures and also their absorption and bioactive properties. The data found on literature consider Pulsed Electric Fields as a promising alternative for food preservation technology due to its resemblance to pasteurization process and small damages on sensory characteristics and food nutritive quality, and so can be used alone or as a complement on thermal processes.

KEY-WORDS: FOOD PRESERVATION; ELECTRIC PULSE; MICROBES INACTIVATION.

\section{REFERÊNCIAS}

1 ABABOUCH, L. H.; CRIMIT, L.; EDDATRY, R.; BUSTA, F. F. Thermal inactivation kinetics of Bacillus subtilis spores suspended in buffer and oils. Journal of Applied Bacteriology, v.78, p. 669-967, 1995.

2 ARONSSON, K.; RÖNNER, U.; BORCH, E. Inactivation of Escherichia coli, Listeria innocua and Saccharomyces cerevisiae in relation to membrane permeabilization and subsequent leakage of intracellular compounds due the pulsed electric field processing. International Journal of Food Microbiology, v. 99, n. 1, p. 19-32, 2005.

3 BAZHAL, M. I.; LEBOVKA, N. I.; VOROBIEV, E. Pulsed field treatment of apple tissue during compression for juice extraction. Journal of Food Engineering, v. 50, p. 129-139, 2001.

4 BARSOTTI, L. et al. Effects of high voltage electric pulses on protein-based food constituents and structures. Trends in Food Science \& Technology, v. 12, n. 3-4, p. 136-144, 2001.

5 BENDICHO, S. et al. Effect of high intensity pulsed electric fields and heat treatments on vitamins of milk. Journal of Dairy Research, v. 69, p. 113-123, 2002.

6 DEVLIEGHERE, F.; VERMEIREN, L.; DEBEVERE, J. New preservation technologies: possibilities and limitations. International Dairy Journal, v. 14, n.4, p.273-285, 2004.

7 FERNÁNDEZ-DíAZ, M. D. et al. Effects of pulsed electric fields on ovoalbumin solutions and dialized egg white. Journal of Agricultural and Food Chemistry, v. 48, p. 2332-2339, 2000. 
8 GÓNGORA-NIETO, M. M. et al. Food processing by pulsed electric fields: treatment delivery, inactivation level, and regulatory aspects. Lebensmittel-Wissenschaft and Technologie, v.35, p.375-388, 2002.

9 GOULD, G. W. Biodeterioration of foods and an overview of preservation in the food and dairy industries. International Biodeterioration \& Biodegradation, v. 36, p. 267-277, 1995.

10 GRAHL, T.; MÄRKL, H. Killing of micro-organisms by pulsed electric fields. Applied Microbiology and Biotechnology, v. 45, p. $148-157,1996$.

11 HAUBEN, K. J. A. et al. Escherichia coli mutants resistant to inactivation by high hidrostatic pressure. Appl. Environ. Microbiol., v. 63, p. 945-950, 1997.

12 HÜlShEGER, H.; POTTEL, J.; NIEMMAN, E. G. Killing of bacteria with electric pulses of high field strength. Radiat. Environ. Biophys., v.20, p.53-65, 1981.

13 HÜLSHEGER, H.; POTTEL, J.; NIEMMAN, E. G. Electric field effects on bacteria and yeast cells. Radiat. Environ. Biophys., v.22, p.149-162, 1983.

14 JAYARAM, S.; CASTLE, G. S. P.; MARGARITIS, A. Kinetics of sterilization of Lactobacillus brevis cells by the application of high voltage pulses. Biotechnol. Bioeng., v. 40, n.11, p. 14212-1420, 1992.

15 JEYAMKONDAN, S.; JAYAS, D. S.; HOLLEY, R. A. Pulsed electric field processing of foods: a review. Journal of Food Protection, v.62, n.9, p.1088-1096, 1999.

$16 \mathrm{KEITH}$, W. D. et al. Pulsed electric fields as a processing alternative for microbial reduction in spice. Food Research International, v. 30, p. 195-191, 1997.

17 LADO, B.H.; YOUSEF, A.E. Alternative food-preservation technologies: efficacy and mechanisms. Microbes and Infection, v. 4, p. 433-440, 2002.

18 LEBOVKA, N. I. et al. Temperature enhanced electroporation under the pulsed electric field treatment of food tissue. Journal of Food Engineering, v. 69, n. 2, p. 177-184, 2005.

19 LINDGREN, M. et al. Simulation of the temperature increase in pulsed electric field (PEF) continuous flow treatment chambers. Innovative Food Science and Technologies, v.3, p. 233-245, 2002.

20 MARQUEZ, V. O.; MITTAL, G. S.; GRIFFITHS, M. W. Destruction and inhibition of bacterial spores by high voltage pulsed electric fields. Journal of Food Science, v.62, p. 399-409, 1997.

21 PEREZ, O. E.; PILOSOF, A. M. R. Pulsed electric fields effects on the molecular structure and gelation of $\beta$-lactoglobulin concentrate and egg white. Food Research International, v. 37, p.102-110, 2004.

22 POTHAKAMURY, U. R. et al. Inactivation of Escherichia coli and Staphylococcus aureus in model foods by pulsed electric field technology. Food Research International, v.28, n.2, p. 167-171, 1995.

23 QIN, B. L. et al. Food pasteurization using high intensity pulsed electric fields. Journal Food Technology, v. 49, n. 12, p.55-60, 1995.

24 RODRIGO, D. et al. Study of inactivation of Lactobacillus plantarum in orange-carrot juice by means of pulsed electric fields: comparison of inactivation kinetics models. Journal of Food Protection, v. 64, p. 259-263, 2001.

25 ROSS, A. I. V. et al. Combining nonthermal technologies to control foodborne microorganisms. International Journal of Food Microbiology, v. 89, n. 2-3, p. 125-138, 2003.

26 SALE, A. J. H.; HAMILTON, W. A. Effects of high electric fields on microorganims I. Killing of bacteria and yeast. Biochimica Biophysica Acta, v. 148, p. 781-788, 1967.

27 SÁNCHEZ-MORENO, C. et al. Pulsed electric fields processed orange juice consumption increases plasm vitamin C and decreases $\mathrm{F}_{2}$-isoprostanes in health humans. Journal of Nutritional Biochemistry, v. 15, p. 601-607, 2004.

28 SEPULVEDA, D. R. et al. Influence of treatment temperature on the inactivation of Listeria innocua by pulsed electric fields. Lebensmittel-Wissenschaft and Technologie, v. 38, p. 167-172, 2005.

29 SPERBER, W. H. Future developments in food safety and HACCP. Food Control., v.9, n. 2-3, p. 129-130, 1998.

30 VEGA-MERCADO, H. et al. Non-thermal food preservation: electric fields. Trends in Food Science \& Technology, v.8, p.151-157, 1997.

31 ZHANG, Q. H. et al. Inactivation of E. coli for food pasteurization by high-strength pulsed electric fields. Journal of Food Process Preserv, v.19, n.2, p.103-118, 1995. 